\title{
SATELLITE-BASED MEASUREMENTS FOR BENCHMARKING REGIONAL IRRIGATION PERFORMANCE IN GOULBURN-MURRAY CATCHMENT
}

\author{
M. Abuzar ${ }^{\text {a, *, A. McAllister }}{ }^{\text {b }}$, D. Whitfield ${ }^{\text {b }}$, K. Sheffield ${ }^{\text {a }}$ \\ Future Farming Systems Research Division (FFSR), Department of Primary Industries (DPI) \\ ${ }^{a}$ FFSR, DPI, 32 Lincoln Square North, Carlton, VIC 3053, Australia \\ ${ }^{\mathrm{b}}$ FFSR, DPI, 255 Ferguson Road, Tatura, VIC 3616, Australia
}

KEY WORDS: Remote Sensing, agriculture, application, image, satellite, temperature

\begin{abstract}
:
Irrigation has a significant impact on regional water resources in south-eastern Australia. It is therefore important that objective assessments of the current use of water are undertaken on a routine basis. New remote sensing technologies now provide an opportunity to assess and monitor water use at farm and catchment scales. This study demonstrates the use of satellite-based estimates of evapotranspiration (ET) and NDVI (Normalised Difference Vegetation Index) in irrigation performance indicators that relate crop water use to crop water requirement (CWR) in the Goulburn-Murray Irrigation Region of South-Eastern Australia. The METRIC energy balance algorithm (Allen et al 2007) was used to derive ET estimates from Landsat satellite data.
\end{abstract}

\section{INTRODUCTION}

Irrigation dominates agriculture in the Goulburn-Murray Irrigation Region of south-eastern Australia. The Catchment, located in Victoria, Australia, between $35^{\circ} 06^{\prime}$ and $36^{\circ} 42^{\prime} \mathrm{S}$ latitudes, and $143^{\circ} 18^{\prime}$ and $146^{\circ} 01^{\prime} \mathrm{E}$ longitudes accounts for an area of about $68,000 \mathrm{sq} \mathrm{km}$, and includes the key irrigation areas of Central Goulburn, Shepparton, Rochester-Campaspe, Pyramid-Boort, Murray Valley and Torrumbarry. It is one of the most important agricultural regions in Australia with major irrigation-based industries that include dairy, horticulture and viticulture enterprises.

Irrigated agriculture consequently has a major impact on available water resources in the region, and the sustainable management of the increasingly limited water resource requires repeated objective assessments of irrigation water use (supply) in relation to the demand for water, set by crop type, crop water requirement (CWR), crop area and seasonal weather conditions (evaporative demand + rainfall). This study demonstrates the use of Satellite Remote Sensing to support comprehensive, affordable irrigation water use assessments, and improved irrigation management in the Catchment.

The study focused on a fundamental indicator of irrigation performance, namely the relationship between farm total crop water use ('water supply', TWS) and crop water 'demand', measured as CWR. Comparisons of TWS in relation to CWR rapidly identify issues of under- and over-supply of irrigation water on farms.

\section{METHODS}

The study compared measures of TWS and CWR in the irrigation season 2008-09. Landsat satellite images for 2008-09 were used to identify areas of active irrigation, and to derive estimates of CWR. Pixel-scale estimates of CWR were derived from the standard equation:
$\mathrm{CWR}_{\mathrm{P}}=\sum(\mathrm{Kc} \mathrm{ETr}-\mathrm{R})$ where $\mathrm{Kc}$ was the crop- and field-specific 'crop coefficient' appropriate to the irrigated field, ETr was 'alfalfa' 'tall-crop' reference crop evapotranspiration (Allen et al 2006), and R was 'effective' rainfall (McAllister et al 2009). The summation in Equation 1 depended on crop, and was extended over the seasonal duration of active irrigation of a crop. Field-scale and farm-scale estimates of CWR were derived by integrating values of $\mathrm{CWR}_{\mathrm{P}}$ over pixels-within-fields and fields-within-farms, respectively.

Meteorological data appropriate to the calculation of ETr and R were sourced from SILO website (http://www.longpaddock.qld.gov.au/silo/) for two locations (Shepparton and Swan Hill). NDVI-dependent crop- and region-specific estimates of Kc (Whitfield et al 2011) were used to make pixel-specific estimates of Kc for use in Equation 1.

Crop- and region-specific estimates of Kc made according to Whitfield et al (2011) were based on relationships that described the dependence of satellite-derived rates of ET on associated measures of NDVI. Satellite measures of ET and NDVI were made using a variant of the METRIC method (Allen et al 2007) that used the empirical relationship of Teixeira et al (2009) to describe surface roughness as a function of NDVI and surface albedo.

Horticulture in the Goulburn-Murray Irrigation Region is dominated by long-lived perennial plantings. Land use and crop types on horticultural fields are therefore relatively stable over time. The areal extent of fields within horticultural farms and associated crop type were sourced from land use maps provided by Shepparton Preserving Co. (SPC).

By contrast, both annual and perennial pastures are important on irrigated dairy farms. Seasonal variations in satellite-derived representations of the VIT space, which describes land surface temperature as a function of NDVI (Abuzar et al 2008), were used to categorise irrigated dairy fields into annual and perennial classes.

\footnotetext{
* Corresponding and presenting author:mohammad.abuzar@dpi.vic.gov.au
} 
Farm cadastral data were sourced from Victorian Department of Sustainability and Environment (DSE). Measures of water supplied to farms in the period, January to April 2009, were sourced from the Victorian Water Register (VWR), maintained by DSE (http://www.waterregister.vic.gov.au/). Farm-scale data were aggregated to district (pod) scale for regional reporting purposes.

Seven cloud-free images of Landsat 5 were acquired for the study (Table 1). The images were sourced from the USGS (http://earthexplorer.usgs.gov). The selection of images represented the traditional irrigation period during spring, summer and autumn seasons in northern Victoria (irrigation is not normally required in the period, June - August, when rainfall usually exceeds evaporative demand). All images were radiometrically corrected prior to analysis. Digital numbers were converted into physical units of at-sensor-radiance, top-ofatmosphere (TOA) reflectance, and at-sensor brightness temperature to a $30 \mathrm{~m}$ spatial resolution, using the current equations available for Landsat-5 (Chander et al 2009).

\begin{tabular}{|c|c|}
\hline Acquisition Date & Scene (Path / Row) \\
\hline 10 Oct 2008 & $94 / 85$ \\
04 Nov 2008 & $93 / 85$ \\
14 Jan 2009 & $94 / 85$ \\
23 Jan 2009 & $93 / 85$ \\
13 Apr 2009 & $93 / 85$ \\
20 Apr 2009 & $94 / 85$ \\
08 May 2009 & $92 / 85$ \\
\hline
\end{tabular}

Table 1. Landsat 5 TM images used in the study.

\section{RESULTS}

Spatial distribution of CWR showed significant variation at pod-level during Jan-Apr 2009 (Figure 1). Large parts of Pyramid-Boort and Torrumbarry areas in the west had CWR under 1000ML. Higher numbers of CWR (reaching up to 9440 ML) were in Central Goulburn, Shepparton and Murray Valley irrigation areas.

Total water supply at pod-level varied from near zero to over 5000 ML during January-April 2009 (Table 2). Spatial distribution of TWS (Figure 2) showed similar pattern as of CWR (Figure 1). Parts of eastern Torrumabrry, Central Goulburn, Shepparton, and Murray Valley had fairly high water supply whereas large parts of Pyramid-Boort areas received very little water.

The ratio of TWS and CWR ranged between near zero and 13 (Table 2). TWS and CWR showed a strong relationship (Figure 3 ), which supports the use of these data to underpin a benchmark. The regional distribution of the ratio showed a considerable spatial variation. Lower values $(\approx 1.0)$ where supply is near or below demand, were found in the eastern part of the Catchment. Pyramid-Boort and the western part of Torrumbarry irrigation area showed higher values of the CWR: TWS. Irrigation intensity (ML/ha) ranged between 0 and 20 ML/ha. Western areas had higher irrigation intensities as well as those on the edge of the irrigation systems. A large part of the Catchment had water use $<5$ ML/ha in Jan-Apr 2009.

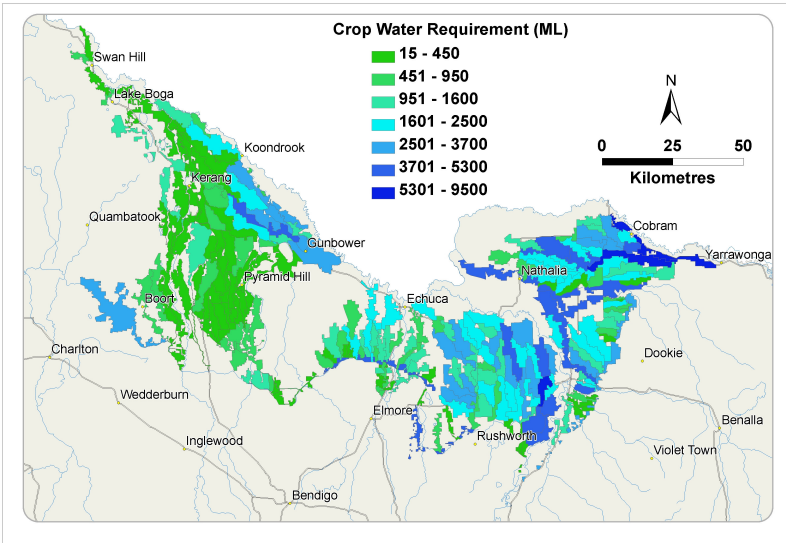

Figure 1. Crop water requirement (CWR) during January April 2009 in Goulburn-Murray catchment.

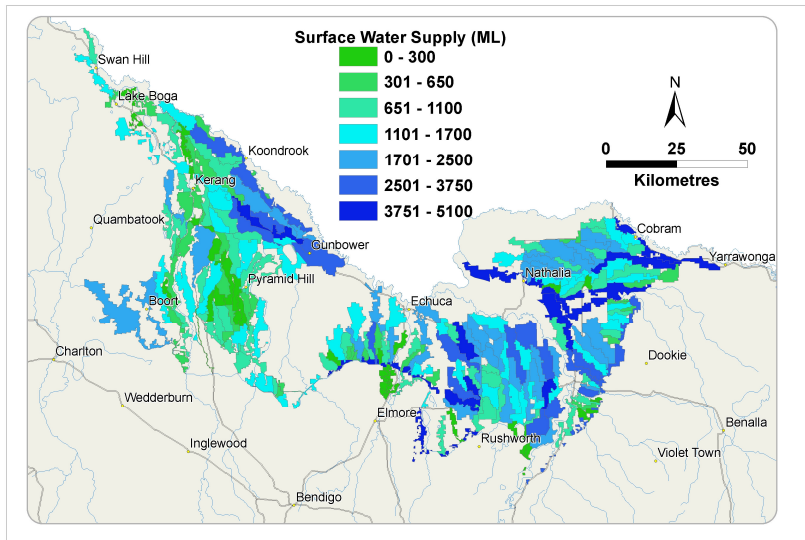

Figure 2. Total surface water (water supply) during January April 2009 in Goulburn-Murray catchment.

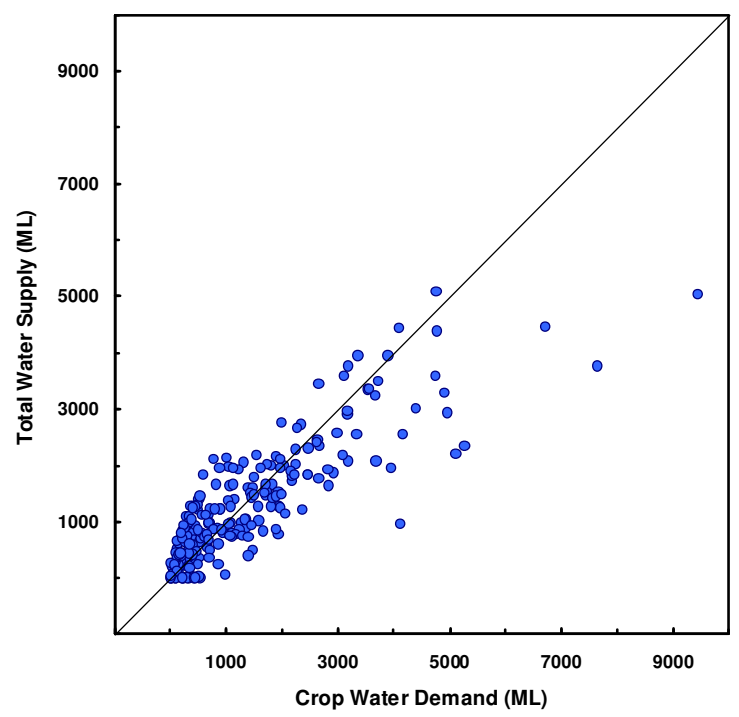

Figure 3. Crop water requirement vs water supply in GoulburnMurray catchment during January - April 2009. The line shows the relationship, TWS $=$ CWR, where farm water supply and water demand are in approximate balance. 


\begin{tabular}{|lccc|}
\hline & TWS:CWR & CWR (ML) & TWS (ML) \\
\hline MIN & 0.06 & 14.91 & 0.00 \\
MAX & 13.14 & 9440.57 & 5089.22 \\
Mean & 1.53 & 1384.97 & 1296.51 \\
SD & 1.30 & 1438.61 & 1035.81 \\
\hline
\end{tabular}

Table 2. Summary statistics of CWR and TWS, Jan-Apr 2009 $(\mathrm{n}=230)$.

\section{DISCUSSION}

Irrigation benchmarking is a process of assessing irrigation performance by using measurable indicators to support decision making for improvement in irrigation (Rodriguez-Diaz et al. 2008, Santos et al. 2010). One of the key performance indicators is TWS to an 'irrigation unit' in relation to the CWR within that spatial unit (McAllister 2008). This study demonstrated the feasibility of using TWS:CWR indicator in the context of Australian irrigated crops. The use of Satellite Remote Sensing for the estimates of ET and CWR is relatively new (Santos et al. 2010) as compared to the traditional FAO methodology (Allen et al., 1998). Remote sensing approach has the advantage of providing the continuous coverage of ET (actual) and CWR in contrast to point estimates by traditional method.

The ratio TWS:CWR is a single value indicator and is easy to interpret. However the single values of indicator do not provide adequate perspective of the volume of irrigation and water use involved. It is desirable to examine the TWS and CWR values separately. The scatter graph (Figure 3 ) shows the wide range of values at pod-level. For the whole Catchment, water supply was short of water demand but as the graph shows, there were considerable variations.

\section{CONCLUSIONS}

The results show that the satellite-derived measurements (Crop water use, crop water requirement, irrigation areas) in combination of water supply information from VWR, provide the capacity to customise irrigation performance indicators to suit particular time period and particular crops. The approach demonstrates the ability to report water use in a spatial context, which is potentially scalable from farm to Catchment. The results of this study will be used to support an irrigation water use appraisal system and the reporting of water use efficiency as part of the evaluation process for modernisation in the Catchment.

\section{REFERENCES}

Abuzar, M., McAllister, A., Whitfield, D., Morse-McNabb, E., Savige, C., 2008. Remote sensing tools and approaches to integrated irrigation water management at farm and regional scales. 14th Australasian Remote Sensing \& Photogrammetry Conference, Darwin.

Allen, R.G., Pereira, L.S., Raes, D., Smith, M., 1998. Crop evapotranspiration. Guidelines for computing crop water requirements. FAO Irrigation and Drainage Paper 56, Rome, Italy, $300 \mathrm{pp}$.

Allen, R. G., Tasumi, M., Trezza, R., 2007. Satellite-based energy balance for mapping evapotranspiration with internalised calibration (METRIC) -Model. Journal of Irrigation and Drainage Engineering. ASCE, 133, pp. $380-$ 394.

Chander, G., Markham, B. L., Helder, D. L., 2009. Summary of current radiometric calibration coefficients for Landsat MSS, TM, ETM+, and EO-1 ALI sensors. Remote Sensing of Environment, 113(5), pp. 893-903.

McAllister, A., 2008. Irrigation Water Use Efficiency Benchmarking, Final Report. Department of Primary Industries, Future Farming Research Division, Tatura.

McAllister, A., Whitfield, D., Abuzar, A., Morse-McNabb, E., 2009. Regional Water Use Monitoring. Paper presented at Surveying \& Spatial Sciences Institute Biennial International Conference, 28 September - 2 October 2009, Adelaide Convention Centre, Adelaide, Australia.

Rodriguez-Diaz, J. A., Camacho-Poyato, E., Lopez-Luque, R., Perez-Urrestarazu, L., 2008. Benchmarking and multivariate data analysis techniques for improving the efficiency of irrigation districts: An application in Spain. Agricultural Systems, 96, pp.250-259.

Santos, C., Lorite, I., Tasumi, M., Allen, R., Fereres. E., 2010. Performance assessment of an irrigation scheme using indicators determined with remote sensing techniques. Irrigation Science, 28(6), pp. 461-477.

Teixeira, A. H. d. C., Bastiaanssen, W. G. M., Ahmad, M. D., Bos, M. G., 2009. Reviewing SEBAL input parameters for assessing evapotranspiration and water productivity for the Low-Middle Sao Francisco River basin, Brazil. Part A: Calibration and validation. Agricultural and Forest Meteorology, 149, pp. 462-476.

Whitfield, D., McAllister, A., Abuzar M., Sheffield, K., O'Connell, M., McClymont, L., 2010. Measurement, monitoring and reporting systems for improved management of farm and regional water resources in Australia: Final Report. Department of Primary Industries, State of Victoria.

Whitfield, D. M., O'Connell, M. G., McAllister, A., McClymont, L., Abuzar, M., Sheffield, K., 2011. SEBALMETRIC estimates of crop water requirement in horticultural crops grown in SE Australia. Acta Hort. 922, pp. 141-148.

\section{ACKNOWLEDGEMENT}

This work was funded by the Victorian Department of Primary Industries (DPI) and the Victorian Department of Sustainability and Environment (DSE). 